\title{
Human-centered robotics applied to gait training and assessment
}

\author{
Robert Riener, Dr-Ing; ${ }^{1-2 *}$ Lars Lünenburger, Dr rer nat; ${ }^{2}$ Gery Colombo, PhD $^{2-3}$ \\ ${ }^{1}$ Rehabilitation Engineering Group, Automatic Control Laboratory, Swiss Federal Institute of Technology (ETH), \\ Zurich, Switzerland; ${ }^{2}$ Spinal Cord Injury Center, University Hospital Balgrist, University of Zurich, Zurich, \\ Switzerland; ${ }^{3}$ Hocoma, AG, Volketswil, Switzerland
}

\begin{abstract}
Robot-aided gait training can increase the duration and number of training sessions while reducing the number of therapists required for each patient. However, current automated gait trainers do not adapt their movement to the patient's muscular efforts and passive musculoskeletal properties. Furthermore, robot-aided training without therapists lacks the feedback required for patient assessment. In this article, we present results from the literature and our research to provide an overview of novel human-centered strategies for robot behaviors that are patient-cooperative and support motorfunction assessment. Combining robot-aided training with robot-aided assessment will likely make future gait therapy easier, more comfortable, and more efficient. Broad clinical testing is still required for proving this assumption.
\end{abstract}

Key words: biofeedback, gait, gait therapy, human-centered, motor-function assessment, patient-cooperative, rehabilitation, robot-aided training, spasticity, treadmill training.

\section{INTRODUCTION}

\section{Human-Centered Robotics}

Within the last 10 to 15 years, robots have become increasingly common in nonindustrial environments, such as private homes, hospitals, and service areas. These robots are often called "human-centered" or "humanfriendly" systems because of the close interaction between the robotic manipulation system and the human being [1-3]. This close interaction can include contactfree sharing of a common workspace or direct physical human-machine contact.
In comparison with the traditional metrics of performance with industrial robots in structured environments, human-centered robot interaction implies a totally different set of requirements for performance measurement [2]. Such requirements include safety, flexibility, mechanical compliance, gentleness, adaptability toward the user, ease of use, communicative skills, and even humanoid appearance and behavior.

Several groups claim that human-centered robots must be autonomous, easy to use, and capable of providing a high level of comfort, functionality, and pleasure [4]. Heinzmann and Zelinsky added that human-centered robots should have natural communication channels [1], including not only language but also facial gestures and expressions [5].

Incorporation of particular user-cooperative control strategies is highly challenging whenever the human user and robot are in direct (mechanical) contact. In many applications, the goal is for the robot to detect the user's

\footnotetext{
Abbreviations: $\mathrm{CP}=$ cerebral palsy, $\mathrm{CTI}=$ Commission for Technology and Innovation, EMG = electromyographic, MAS $=$ modified Ashworth scale, MS = multiple sclerosis, PDMR = patient-driven motion reinforcement, $\mathrm{SCI}=$ spinal cord injury, TBI = traumatic brain injury, VR = virtual reality.

* Address all correspondence to Robert Riener, Dr-Ing; Professor for Rehabilitation Engineering, Automatic Control Laboratory, ETH Zurich, Physikstr. 3, ETL I 24.2, CH-8092 Zurich, Switzerland; +41-44-632-6679 or $+41-44-632-2828$; fax: +41-44-632-1211. Email: riener@mavt.ethz.ch

DOI: 10.1682/JRRD.2005.02.0046
} 
movement intention and follow him or her rather than impose a predefined movement on the user. For example, application of impedance control laws allows the user to deviate from a predefined reference trajectory [6-8]. Other researchers have introduced adaptive control methods that adjust the robot behavior to the user and, thus, make the technical components more flexible [9] and easier to use. Ikeura et al. have developed humanfriendly robotic approaches in which the robot copies the human characteristics while helping the user carry an object [10]. Lum et al. have developed a similar system in which a robotic apparatus supports a stroke patient's paralyzed hand to correct the orientation of an object carried by the patient (e.g., a cafeteria tray) [11].

The application of human-centered robots in rehabilitation is not new. Bien and Stefanov define humancentered rehabilitation robots as those which perform their functions without disturbing the user or causing him or her any pain, inconvenience, or movement restriction [4]. However, in the rehabilitation field, most human-centered robot applications are limited to the home-assistance tasks of bedridden or elderly subjects [5,12-13].

This article applies novel human-centered principles to robot-aided treadmill training. We present promising methods from the literature as well as our own research that show that rehabilitation robots can behave in a patient-cooperative way and automatically assess motor functions upon mechanical interaction with the patient. Human-centered rehabilitation robotics may not only make operation of robot-aided treadmill training easier but also increase the therapeutic outcome.

\section{Rationale for Treadmill Training}

Task-oriented repetitive movements can improve muscular strength and movement coordination in patients with impairments due to neurological or orthopedic problems. A typical repetitive functional movement is human gait. For example, weight-supported treadmill training has been shown to improve gait and lower-limb motor function in patients with locomotor disorders [14-30]. Manually assisted treadmill training has been used for more than 10 years as a regular therapy for patients with spinal cord injury (SCI) [14-21] or stroke [22-27]. Numerous clinical studies (with limited sample sizes) support the efficacy of such training. More specifically, for hemiparetic patients, weight-supported treadmill training has been shown to improve balance [22,25], lower-limb motor recovery [22-23,25], walking speed
[22,25-26], endurance [27], and other important gait characteristics, such as symmetry, stride length, and double stance time [22,26]. Preliminary studies indicate that these positive therapeutic effects are also obtained in patients with other pathologies, such as multiple sclerosis (MS), Parkinson's disease, and traumatic brain injury (TBI) [28-30].

In a new study, Barbeau and Visintin have shown that partial weight-supported treadmill training in severely impaired stroke subjects results in better walking and postural abilities than gait training in which patients bear their full weight [31]. This result shows that, for an optimal therapeutic outcome, strategies for gait retraining may have to change according to the patient's neurological severity. Studies in patients with chronic SCI also showed benefits [29].

Two recent systematic reviews evaluated the efficacy of body-weight supported treadmill training for stroke patients [32-33]. In the first, Teasell et al. pointed out the conflicting evidence among the different studies [32]. In the second, Moseley et al. concluded that treadmill training and/or body-weight support did not affect functional outcome as compared with conventional overground gait training [33]. These studies show that further active investigations are still needed. Adequately sized randomized clinical trials have not yet been reported that sufficiently prove that treadmill training with body-weight support is more effective than, for example, usual-dose intensity-matched physical therapy.

\section{Human-Centered Robotics Applied to Treadmill Training}

Manually assisted treadmill training has several major limitations. The training is labor-intensive; therefore, training duration is usually limited by personnel shortages and therapist, not patient, fatigue. Furthermore, therapists often experience back pain because the training is performed in an ergonomically unfavorable seating posture. Consequently, training sessions are shorter than may be required for an optimal therapeutic outcome. Finally, manually assisted treadmill training lacks repeatability and objective measures of patient performance and progress.

In contrast, the duration and number of sessions in automated (i.e., robot-aided) gait training can be increased while reducing the number of therapists required for each patient. Indeed, one therapist may be able to train two or more patients in the future. Perhaps 
more importantly, because the gait patterns imposed by the robot assistance are consistent and customized to the patient, appropriate afferent sensory input can be activated. This input is believed to be critical in modulating the timing and amplitude of lower-limb muscle activity [34]. In particular, an automatic gait trainer that is based on an actuated orthosis principle (exoskeleton) can move the leg in a defined trajectory. Thus, a higher load can be induced through the stance leg, which results in a concomitant increase in afferent input.

Current automated gait trainers, such as the Lokomat (Hocoma, AG, Volketswil, Switzerland) [35], the Ambulation-assisting Robotic Tool for Human Rehabilitation and the pelvic assist manipulator (known as ARTHuR and PAM, respectively; not commercially available) [3637], the GaitTrainer (Reha-Stim, Berlin, Germany) [38], the Robotic Walking Simulator (not commercially available) [39], and the Dual Stewart Platform Mobility Simulator (not commercially available) [40], do not (or do not fully) adapt their movement to the activity or passivity of the patient, whose limbs will be moved along a predefined fixed trajectory. Furthermore, neither the patient nor the therapist is informed about the patient's muscle activity and motor-control performance. To date, the devices are not able to perform inter- and posttherapy patient assessment.

Current research efforts are directed at the development of "patient-cooperative" or "subject-centered" strategies that will recognize the patient's movement intention and motor abilities in terms of muscular efforts, feed the information back to the patient, and adapt the robotic assistance to the patient's contribution. The best control and display strategies may do the same as a qualified human therapist; i.e., they will assist the patient's movement only as much as necessary and inform the patient how best to coordinate voluntary muscle efforts for a particular motion. Therefore, the patient actively learns the spatiotemporal patterns of muscle activation associated with normal gait.

Further developments focus on the design of automated patient-assessment strategies. Recorded data from joint angles, velocities, and torques can be processed for quantification of the biomechanical and neurological states of the patient during or after robot-aided training. Parameters such as joint range of motion, maximum voluntary muscle force, or level of spasticity may provide the therapist with valuable information that can be applied to the patient's rehabilitation process.

\section{Advantages of Robot-Aided Treadmill Training with Lokomat}

The human-centered strategies presented in this article are based on the automated gait trainer Lokomat [35]. The Lokomat is a bilateral robotic orthosis that is used along with a body-weight support system and controls patient leg movements in the sagittal plane (Figure 1). The Lokomat hip and knee joints are actuated by linear drives, which are integrated in an exoskeletal structure. A rubber foot lifter induces passive ankle dorsiflexion during the swing phase. The patient's legs are moved with highly repeatable predefined hip- and knee-joint trajectories on the basis of a position-control strategy. Hip- and knee-joint torques are determined from force sensors integrated inside the Lokomat $[9,41]$.

Since the Lokomat became commercially available in 2000, it has been used for gait training in individuals with various medical diagnoses. To date, several studies have examined the therapeutic and functional effects of gait training with the Lokomat in the SCI, stroke, and TBI patient populations.

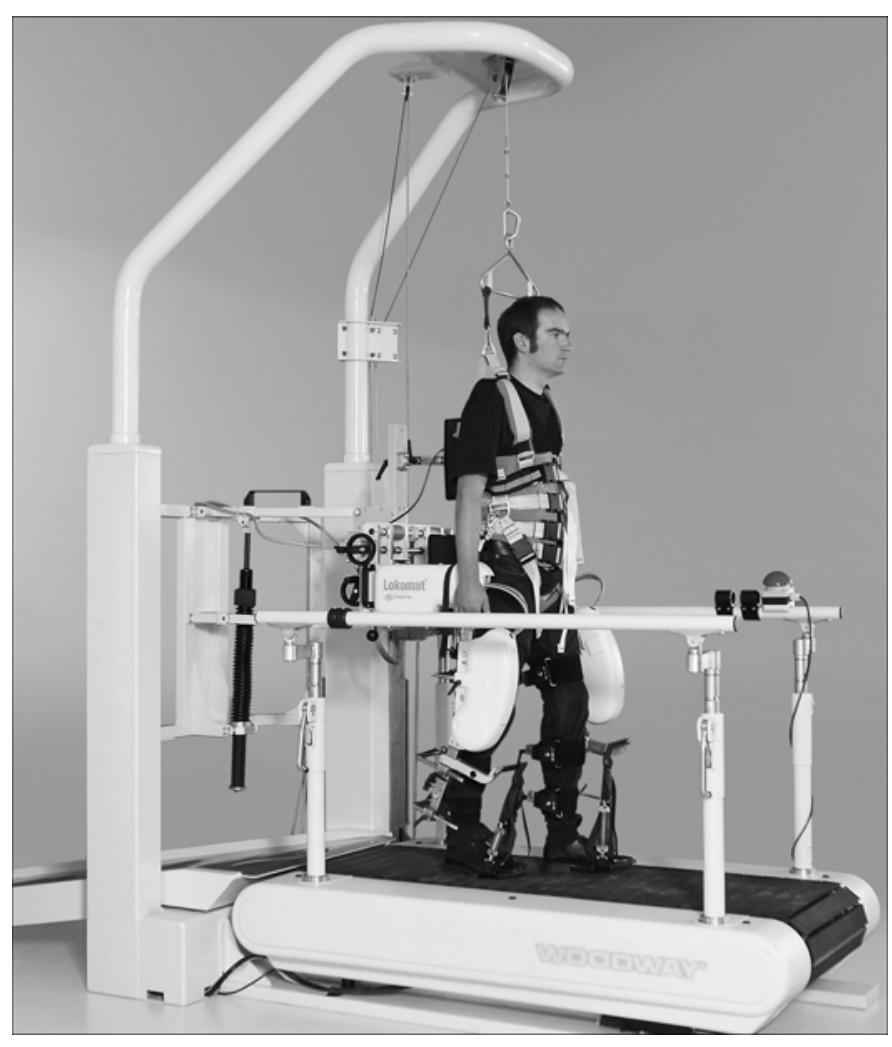

Figure 1.

Lokomat robotic gait orthosis (Hocoma, AG, Volketswil, Switzerland). 
In one study, Lokomat gait training had a modest effect on cardiovascular intensity in a single patient who had sustained a motor complete SCI. Despite the patient's inability to actively assist with walking, Lokomat gait training increased heart rate, oxygen consumption, and minute ventilation [42]. Whether patients with various degrees of incomplete SCI can be aerobically trained and whether this can alter cardiovascular and metabolic functions still need further investigation. A secondary goal of robot-aided training is assisting in cardiovascular and metabolic exercise. A large number of patients with SCI could potentially benefit from aerobic exercise [43]. Wirz et al. examined individuals who were more than 2 years postmotor incomplete [29]. While aerobic exercise only slightly influenced balance and gait kinematics, the investigators found significant improvements in overground walking speed and endurance. Similar improvements in overground walking speed, endurance, and isolated muscle strength were observed in a study with several patients with acute SCI [44].

In a separate study with eight individuals with TBI, a temporary digression was observed in overground walking speed and endurance performance during the initial days of Lokomat gait training [45]. By the end of training, however, significant improvements in overground gait speed and endurance, combined with improvements in spasticity and muscle strength scores, were observed.

A single-case or ABA design study with 16 stroke patients of different etiologies revealed greatly improved function, muscle strength, and walking endurance [46]. The patients' walking speed and ability to perform selective movements were not enhanced. In both treatment groups, Lokomat gait training was superior to training with conventional physiotherapy. After training, patients walked more symmetrically with improved ankle dorsiflexion during the swing phase, demonstrated a stable stance phase with reduced spasticity, and developed adequate equilibrium reactions [46].

The Lokomat has been suggested to be predestined for patients with acute SCI who are too weak to walk overground without external support and thus require the assistance of several therapists to perform body-weightsupported treadmill training [44].

\section{PATIENT-COOPERATIVE MOTION GENERATION}

\section{Overview}

Patient-cooperative strategies automatically recognize the patient's movement intention, muscular efforts, and passive musculoskeletal constraints and adapt the robotic assistance to the patient. In this section, we present patient-cooperative strategies that record the patient's movement efforts so as to make the robot behavior flexible and adaptive. Three different technical concepts were applied to the Lokomat gait trainer: (1) impedance-control methods that make the Lokomat soft and compliant, (2) adaptive-control methods that adjust the reference trajectory and/or controller to the individual patient, and (3) a motion-reinforcement strategy that supports patientinduced movements. First experimental results on a nondisabled subject and a subject with paralysis show that the idea of patient-cooperative control technically works [9,41,47-48].

Subsequent studies will carry out a broad clinical evaluation for assessing the therapeutic effects of these patient-cooperative strategies. An important question to be answered by this evaluation is whether patientcooperative strategies can potentially stimulate active participation (i.e., motivation). For example, will muscle activation that affects the patient's walking pattern produce a feeling of success? Another question is whether patient-cooperative strategies maximize the therapeutic outcome compared with standard overground gait training and position-controlled treadmill training.

\section{Impedance Control}

Since Hogan first introduced impedance controllers more than 20 years ago, they have become well established in the fields of robotics and human-system interaction [6-8]. Basically, application of an impedancecontrol strategy to robot-aided treadmill training will allow variable deviation from a given leg trajectory rather than imposing a rigid gait pattern. The deviation depends on the patient's effort and behavior. An adjustable moment is applied at each joint so that the leg stays within a defined range along the trajectory. The moment can be described as a zero order (stiffness) or higher order (usually first or second order) function of angular position and its derivatives. This moment is more generally called "mechanical impedance." Figure 2 depicts a block diagram of an impedance controller as applied to the Lokomat gait trainer [47-49].

The impedance controller was tested on several nondisabled subjects and one subject with incomplete paraplegia [48]. Prior to the impedance-control mode, subjects walked in a position-control loop. Angular deviations increased with increasing robot compliance as the 


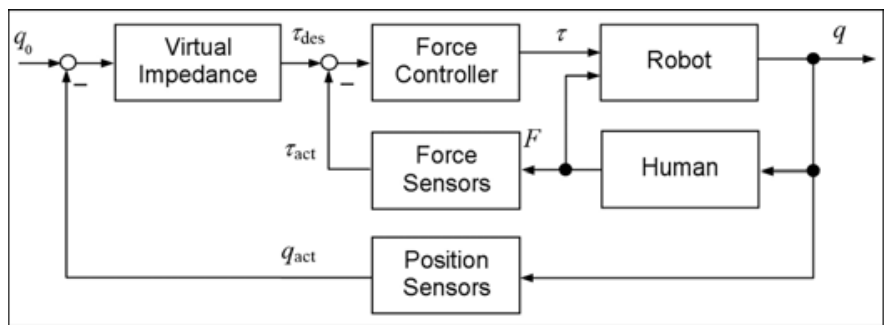

Figure 2.

Impedance-control strategy that makes rehabilitation robot behave compliantly and allows deviation (based on patient's effort and behavior) from given leg trajectory. act $=$ actual, des $=$ desired, $F=$ force, $q=$ motion trajectory, $\tau=$ torque.

robot applied a smaller amount of force to guide the human legs along a given trajectory.

Note that with this controller, the patient has to apply force to achieve a deviation from the preprogrammed fixed trajectory. Thus, patients with severe paraplegia are more or less restricted to the given trajectory and have only limited possibilities to change the gait pattern. On the other hand, involuntary muscle contractions, such as those produced by high muscle tone, spasms, or reflexes, can affect the movement and may yield a physiologically incorrect gait pattern depending on the magnitude of the chosen impedance. In contrast, patients with minor to moderate motor deficits stated that the gentle behavior of the robot felt good and comfortable. The impedancecontrol strategy perfectly suits hemiplegic patients because the intact and the paralyzed contralateral legs can be treated by different impedance values.

The impedance controllers presented in Figure 2 and Riener et al. [47-48] are restricted to fixed reference trajectories. In contrast, some groups have proposed more advanced impedance controllers in which the reference adapts to patient performance $[9,50]$.

\section{Adaptive Control}

The main disadvantage of the impedance-control strategy is that it is based on a fixed-reference trajectory and the actual movement can easily and promptly deviate from the desired one, e.g., after unwanted muscle contractions. Individual adjustments of the gait trajectory are difficult and can only be manually modified based on the therapist's qualitative observations.

Jezernik et al. have developed several control algorithms that automatically adapt the reference trajectory of different reference-based controllers and/or the impedance magnitude of an impedance controller to the indi- vidual patient's desired motion (Figure 3) [9,41]. In these control algorithms, the human represents a component of the control system that influences the overall system behavior (i.e., motion). Since the involvement of human control necessarily promotes patient activity during the exercise, the outcome of movement training with adaptive control of human-robot interaction is expected to result in better therapy outcomes.

Experimental results were obtained via an online adaptation of the reference trajectories of an individual with incomplete SCI $[9,41]$. After following the prespecified Lokomat motion until the 60th step, the patient produced voluntary efforts that changed the reference trajectory such that a modified trajectory (the patient's preferred) was obtained. The adaptation of particular gait parameters resulted in a considerable change in hip reference trajectory.

The adaptation algorithms demonstrated that patientdriven training is possible. The reference trajectory changes in a way that minimizes interaction forces between the patient and the Lokomat. The strategy is robust with respect to nonrepetitive undeliberate muscle contractions (e.g., spasms). Experiments have shown that the best performance was achieved by a combined adaptive and impedance controller with the advantages of both strategies [41].

\section{Patient-Driven Motion Reinforcement}

Patient-driven motion reinforcement (PDMR) control was first presented by Riener and Fuhr for the control of FES-supported, patient-induced standing-up and sittingdown movements [51]. Here, the actual movement initiated by the patient is recorded and fed into an inverse dynamic patient model for determination of the robot

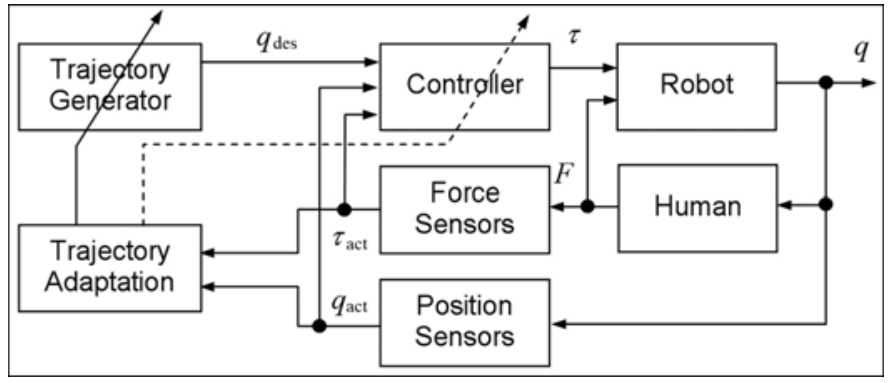

Figure 3.

Adaptive-control strategy that allows rehabilitation robot to automatically adapt to patient's desired motion. act $=$ actual, des $=$ desired, $F=$ force, $q=$ motion trajectory, $\tau=$ torque. 
moment contribution that maintains the patient-induced movement (Figure 4). This means that the patient has to apply some voluntary efforts to obtain a movement that is supported by the robot. A scaling factor $K$ can be introduced to vary the supporting moment.

The PDMR controller was tested on several nondisabled subjects and one subject with paralysis, which enabled them to walk at their own walking speeds and patterns. The Lokomat, as well as the treadmill speed, adapt to human muscle efforts and support the patient's leg movement, e.g., by compensating for gravity- and velocity-dependent effects. To use this controller, the patient must have sufficient voluntary force to induce the robot-supported movement. For guiding patients with stronger motor deficits, the PDMR controller can be combined with the just-mentioned reference-based impedance controller.

\section{Potential Advantages of Patient-Cooperative Controllers}

Patient-cooperative strategies are expected to stimulate active participation by the patient. Such strategies may also potentially increase the patient's motivation because muscle activation changes will be reflected in the walking pattern and cause a consistent feeling of success. Furthermore, the gait variations introduced by the patient-cooperative controllers yield afferent feedback variations that retrain the neural networks in the spinal cord. This feedback can challenge the neuronal systems and lead to favorable training effects in SCI and hemiparetic patients [52-53].

The principal unanswered question is, Will patientcooperative strategies maximize therapeutic outcome in terms of reduced therapy duration and improved gait, posture, and balance quality, as compared with fixed-reference controllers? Furthermore, how do the therapeutic effects

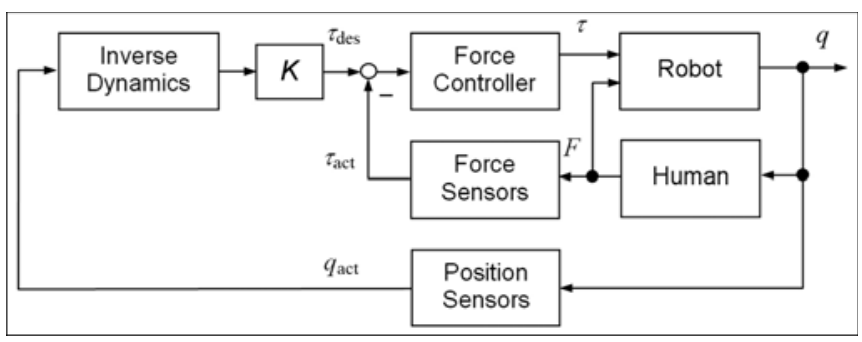

Figure 4.

Example of patient-driven motion reinforcement control strategy that supports patient-induced movements. act $=$ actual, des $=$ desired, $F=$ force, $K=$ scaling factor, $q=$ motion trajectory, $\tau=$ torque. change depending on the kind of patient-cooperative controller being applied to the patient?

Further clinical research is required for answering these questions and determining which strategy leads to the best rehabilitation outcome. Further studies are also required to formulate an assignment function between the patient's motor score and the optimal patient-cooperative controller.

\section{BIOFEEDBACK}

\section{Biofeedback Principles}

Natural, as well as artificial, optimization processes require detectable performance quantities, which are optimized in a certain way. In the human body, these performance quantities are obtained by proprioceptive feedback of movements, forces, visual impressions, sound, etc. However, perception may be disturbed or missing either because the user lacks appropriate afferent input from receptors (e.g., after peripheral nervous system injuries) or has not learned to perform the optimization procedure (e.g., after congenital lesions of the central or vegetative nervous system).

In such cases, artificial sensors can be used for recording the performance quantities (or related values that can be used for determining performance) and feeding them back to the user. Because biological quantities are transferred to a biological system (human) via artificial feedback, the term "biofeedback" has been introduced and become widely accepted.

To make the artificial feedback signals perceptible and allow the patient to react to the signal, technical display devices are required, such as graphic monitors, loudspeakers, vibrators, or haptic displays. The kind of display device depends not only on the application and ergonomic issues but also on the pathology (when biofeedback is applied to a patient). For patients with minor lesions, the display can enhance the affected sensory input. In severe cases, another nonaffected perceptible modality can be chosen as a substitute for the affected sensory function and allow the patient to perceive even "invisible" information.

\section{Biofeedback Applied to Gait Rehabilitation}

Several research groups suggest the application of biofeedback principles for gait rehabilitation of patients 
with stroke [32,54-62], cerebral palsy (CP) [63], incomplete paraplegia [64], spina bifida [65], or arthritis [66].

Many studies detect motor functions or performance by electromyographic (EMG) recordings [54-57,63-64]. As an alternative or extension to EMG recordings, kinematic quantities have also been used [56-61,65-69], e.g., joint angles of the ankle [56-57] or the knee [58], the distance between left and right knee joints [59], step length [60,66], and stance duration [61,64,66,68-69]. Kinetic measures have been used as well, such as ground reaction forces and plantar pressure values [68-69]. No study has used biofeedback of joint moments during walking, although such joint moments could be estimated by an inverse dynamic approach.

The recorded signals are processed and fed back to the patients via visual displays $[60,63]$, acoustic displays [58$59,61,64,68]$, or both $[54,57,64,66,69]$. Some research groups also use vibrotactile displays to generate tactile impressions on the skin [65,67-68].

In a simple manner, the information can be presented to the patient only by graphical elements, such as numbers, bars, or graphs. A more advanced method is the application of virtual reality (VR) technologies. Here the measured patient activity, such as gait speed, muscle activity, and leg and foot motion patterns, is displayed by graphical or audiovisual animations and provide a realistic impression to the patient. The goal is for the patient to feel present in a virtual environment while continuously confronted with information about his or her motor performance during the training in an easy, intuitive way. VR can make training therapies more exciting for the patient, thus motivating him or her to train longer and more often. Several research groups have applied VR to physical therapy of upper [70-72] and lower limbs [73-78].

The clinical evidence for a beneficial effect of biofeedback is controversial. Van Peppen et al. did not find a significant difference in gait speed when they pooled 7 appropriate studies out of 16 identified in a systematic literature review [62]. The summary effect size of biofeedback on the active range of motion was also not significant (based on four pooled studies). In comparison, Teasell et al. did not pool results from different studies but rather counted the studies with positive versus negative outcome effects; from this systematic review, eight of nine studies showed a positive biofeedback effect [32].

Wolf and Binder-MacLeod investigated the effects of EMG-biofeedback during arm rehabilitation of 22 patients with hemiplegia [79]. In comparison with a control group $(n=9)$, improved neuromuscular parameters were observed, whereas functional changes were absent. In contrast, Inglis et al. showed that, compared with conventional therapy, biofeedback improved functional properties, such as muscle force, active range of movement, and motor recovery of patients with hemiplegia [80]. Several further studies reported positive functional effects of EMG biofeedback applied to stroke patients [81-82].

In conclusion, we interpret the available evidence as demonstrating a positive effect of biofeedback on motor recovery and see the potential for wider benefit in neurological rehabilitation.

\section{Force-Based Biofeedback with Lokomat}

Optimal training effects during gait training depend on appropriate performance feedback. Compared with manually assisted treadmill training, robot-aided gait training involves a loss of physical interaction between therapist and patient. Thus, assessing the patient's contribution during training and providing necessary feedback and instructions are difficult for the therapist. For the patient, the quality of movement and extent of activity are significant performance measures that are not easily assessed subjectively, particularly when he or she also has deficits in sensation, proprioception, and cognition.

The Lokomat is instrumented with potentiometers and force transducers and, thus, is capable of providing online feedback about joint movement and joint moment production, respectively. Numerous other parameters, such as stride length, gait symmetry, and EMG activity, could also be measured and used as biofeedback values. The challenge, however, is deriving performance (biofeedback) values that can be related to the patient's jointtorque-related activity as the patient is mounted inside a joint-torque-producing device. These values should be adequately comprehensive for training specific aspects of the gait pattern, while enabling easy presentation by graphical, acoustical, or tactile displays to both the patient and the therapist. The patient should be motivated to improve his or her gait pattern during therapy, while the therapist can evaluate the patient's effort, provide instructions, and assess the therapeutic progress.

We previously described implementation of a forcebiofeedback strategy for the Lokomat $[48,83]$. For each gait cycle phase ( $i=1$ for stance, $i=2$ for swing), weighted averages of the torques $T$ measured in the instrumented joint drives ( $j=1$ for hip, $j=2$ for knee) 
are calculated independently and thus yield four biofeedback values $B_{i, j}$ for each stride and leg

$$
B_{i, j}=\frac{\left[\int w_{i, j}(t)\right]\left[T_{i, j}(t) d t\right]}{\int w_{i, j}(t) d t} .
$$

The weight functions $w_{i, j}$ were selected for providing positive biofeedback values when the patient performs therapeutically desirable activities. The torque outputs of the drives give direct information about the patient's activity and performance during movement generation with respect to the reference trajectory provided by the Lokomat. If the patient moves actively and follows the reference trajectory exactly, no interaction torques between the robot and patient will result. Torques in the drives that move the robot itself can be neglected or computationally compensated. If the patient behaves in a passive way (e.g., because of paresis or lack of motivation), the robot has to exert torque additional to the torque required for Lokomat joint rotation to maintain the desired reference trajectory. Conversely, if the patient tries to move faster than the reference trajectory, then the robot requires less torque.

Weight functions were chosen that lead to positive feedback when the patient performs therapeutically desirable movements and negative feedback for nonphysiological movements, e.g., when the patient resists the flexion of the hip during swing phase. For the swing phase, weight functions are proportional to the corresponding joint angular velocity. This condition will favor active hip flexion that supports the swing phase, and positive feedback for the knee joint is given for active flexion in the first half of the swing phase (lifting the foot off the ground) and for extension during the second half (preparing for heel contact). For the stance phase, the most important function is the weight support (i.e., continuous active knee extension). The weight function for the knee was constant.

This approach provides four biofeedback values for each stride and leg. The values are available immediately after each step. The data have to be displayed in an easily accessible fashion because some patients with neurological injuries or diseases who require gait retraining also have cognitive deficits (e.g., deficits that occur after TBI). Thus, such patients benefit from a reduction to one value each gait phase and a visually appealing display (e.g., traffic light or smiley face) to reflect performance, whereas patients with SCI often prefer line graphs that display a complete data set, including a short history of past performance values.

\section{Discussion of Lokomat Biofeedback}

The Lokomat biofeedback approach allows the detection and improvement of gait-phase-dependent kinetic muscle strength. However, this approach does not directly show whether patients will improve their ability to generate physiologically correct kinematic gait patterns. The reason for this limitation is that the biofeedback mode requires the movements to be position-controlled with respect to a predefined reference pattern, which prevents the patients from performing their preferred movement. One of the just-mentioned cooperative-control strategies could be implemented and thus allow deviations from the predefined reference trajectory so that the patients can adapt their movements to an individual and physiologically optimal trajectory. In the future, an advanced biofeedback strategy should be capable of classifying the patient's contributions not only to the desired force but also to his or her movement.

\section{ASSESSMENT}

\section{Assessment Principles}

Performance during gait retraining is not the only important measure in rehabilitation. Additional primary and secondary impairments that originate from TBI or SCI commonly include muscle weakness, spasticity, and joint contractures. Muscle strength, muscle tone, and joint range of motion of the lower limb are parameters that can be measured by a properly instrumented robotic gait device.

Traditionally, muscle strength is clinically evaluated manually and graded on an ordinal scale (British Medical Research Council manual muscle test). Isometric strength can also be measured by handheld dynamometers, which yield an objective measure of force. Furthermore, commercial machines are available that measure isometric or isokinetic muscle strength. For muscle hypertonia, such as spasticity, the manually performed Ashworth scale is commonly used and easily implemented in the clinical setting [84-85]. Other manual tests for assessing spasticity include neurophysiological methods (e.g., elicitation of reflexes [86]) and biomechanical methods (e.g., passive pendulum tests [87-88]). Joint range of motion is 
usually evaluated manually with a passive goniometer that measures the angular extent of movement.

These measures provide important functional improvement indicators for the therapist and patient. Performing each test during each rehabilitation session would be time-consuming. However, tests that measure these parameters could be implemented through appropriate instrumentation of robotic devices. Enhancement of robotic gait trainers is viable because no additional acquisitions are required. For example, force transducers integrated in the hip and knee joints of exoskeletal robotic devices-such as the Lokomat-evaluate muscle strength and voluntary force. Potentiometers offer a convenient method of extracting joint range-of-motion information. Last but not least, imposing joint movements at different speeds and concomitant measurements from force transducers may possibly evaluate passive joint stiffness as well as active and passive muscle properties. Integrating assessment instruments with robotic gait trainers offers advantages to both the therapist and patient in quantitative measures of progress, outcome, cost, and time efficiency.

\section{Automated Spasticity Assessment}

Spasticity is an alteration in muscle activation with increased tone and reflexes. It is a common effect of neurological disorders and injuries that affect the upper motor neuron, e.g., in TBI or SCI. Formally, spasticity is "a motor disorder characterized by a velocity-dependent increase of tonic stretch reflexes (muscle tone) with exaggerated tendon jerks, resulting from hyperexitability of stretch reflexes" [89]. It presents as increased joint resistance during passive movements. Recently, Sanger et al. introduced a more functional rather than physiological definition of spasticity as "a velocity-dependent resistance of a muscle to stretch" [90].

Spasticity can negatively influence limb movement and lead to unwanted, nonfunctional, or even dangerous movements. It can also prevent intended movements because the increased muscle tone or reflexes can counteract the voluntary muscle activation. However, some patients actively rely on their spasticity to support voluntary muscle activation, e.g., to extend the legs while they are standing [91]. For better assessment of the individual advantages and disadvantages of spasticity, exact measurement and assessment of spasticity are important before and after any therapy that may potentially modify spasticity.
A multitude of methods for spasticity assessment can be found in the literature, which reflects the different definitions and clinical requirements of spasticity. Spasticity is most commonly evaluated by the Ashworth scale [84] or modified Ashworth scale (MAS) [85]. In both tests, the examiner moves the patient's limb while the patient remains passive. The examiner rates the encountered mechanical resistance to passive movement on a scale from 0 to 4 , with a higher score indicating more resistance. However, this evaluation is subject to variable factors, such as the speed of the movement used during the examination and the examiner's experience.

Several research groups use isokinetic machines to estimate the level of spasticity. Most groups apply ramp or ramp-and-hold trajectories to generate passive limb movements while estimating the resistive joint torque [92-97]. Other groups use sinusoidal patterns [98] or randomized rectangles [99-100]. This kind of automated spasticity assessment has been tested on subjects with SCI and children with CP. The test-retest reliability of instrumented spasticity measurements is high [101-102]. In Kakebeeke et al.'s study, the reliability of isokinetic measurements increased with the test velocity [97]. The best correlation between instrumented and manual measurements was observed for high and low spasticity levels, whereas correlations appeared inconsistent at medium spasticity levels [103]. The instrumented methods often are not suitable for clinical applications because they are expensive, inconvenient, and much more time-consuming than manual methods.

Spasticity evaluation can also be performed with rehabilitation robots capable of simultaneously measuring joint movement and torque. The advantage of using rehabilitation robots, such as the Lokomat, is that extra time and effort is not required for mounting the measurement system to the patient. The spasticity evaluation can be performed immediately before and after the usual robot-aided training.

\section{Lokomat-Aided Spasticity Assessment}

To use the Lokomat for spasticity evaluation, the patient is lifted from the treadmill by a body-weight support system so that the feet can freely move without touching the ground. Then, the Lokomat performs controlled displacements of each of the four actuated joints, subsequently at different velocities. The trajectories are sine-squared functions that replicate the movements applied by an examiner performing a manual Ashworth 
scale assessment. Measured joint torques $T$ and joint angles $\phi$ are used to calculate the elastic stiffness $K$ as slope of the linear regression as

$$
T=K \phi+T_{0}
$$

Because the recorded torques also include passive physical effects of the Lokomat and the human leg, the measured torque $T$ is compensated for inertial, gravitational, coriolis, and frictional components obtained from an identified segmental model of the orthosis and the human leg [104].

The elastic stiffness of 42 subjects with neurological disorders was correlated with the MAS score that was obtained right before the automated measurement (Figure 5). In general, higher mechanical stiffness was observed in joints with higher spasticity (MAS score 2 to 4). The stiffness values for MAS scores 0,1 , and $1{ }^{*}$ do not differ because these values are classified according to

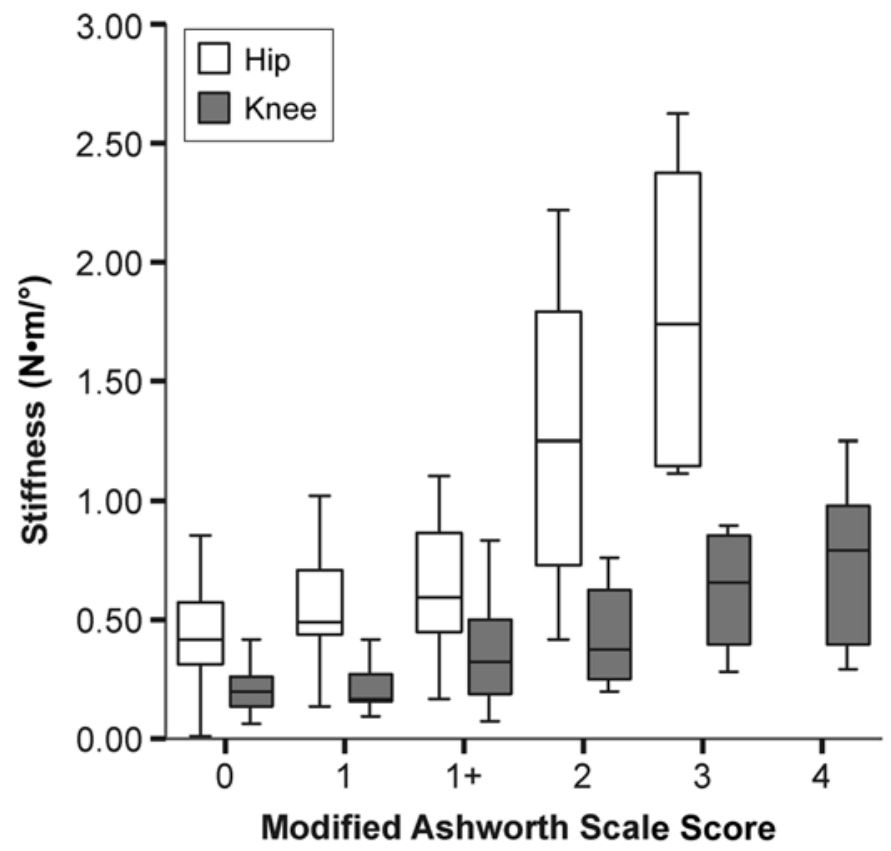

Figure 5.

Relation between measured joint stiffness and manually measured modified Ashworth scale score. Data obtained from 42 subjects with neurological impairments. Boxes depict 25 to 75 percentile, divided by median. Whiskers indicate range of values. $1+$ represents score between 1 and 2 .

* On the MAS, 1+ represents a score between 1 and 2. the presence of transient resistance phases ("catches"), which cannot be detected by the linear regression just presented.

Although experimentally determined stiffness increased with increasing spasticity, a clear relationship between stiffness values and MAS scores could not be established (Figure 5). The correlation between manually determined spasticity and automated stiffness measurement may improve with modified data analysis methods and further experiments with enhanced manual spasticity evaluation procedures (e.g., EMG-based or with more Ashworth scale examiners).

\section{Discussion of Robot-Aided Spasticity Evaluation with Lokomat}

The main advantage of robot-aided spasticity evaluation is that the data obtained are reproducible, comparable, and unaffected by the individual variations usually observed among different examiners performing the Ashworth scale. However, variations in patient positioning within the Lokomat have to be minimized because they may result in erroneous stiffness (or MAS) predictions.

The method is attractive for patients performing robot-aided gait training because no additional efforts are required (i.e., having to put the patient in a separate measurement device). On the other hand, one should note that this kind of spasticity evaluation does not provide insight into the muscle-specific proportioning or neural innervation of the muscles.

\section{Automated Assessment of Biomechanical Quantities with Lokomat}

Further parameters that can be assessed by the Lokomat are maximum voluntary muscle effort, range of motion, and other gait parameters. To estimate the maximum voluntary efforts, the examiner sets the Lokomat to position-control mode with a static hip- and knee-joint angle reference to produce isometric measurement conditions. The examiner instructs the patient to generate joint moments in flexion and extension directions. The moments generated are measured by the force transducers inside the Lokomat and are continuously displayed to the patient and the examiner. Maximum moments for flexion and extension are also computed and displayed. Preliminary tests have been performed with three patients with SCI and four controls.

To measure range of motion, the examiner moves the patient's leg, which is mounted inside the Lokomat, until 
the passive moment produced by the patient's joint reaches a high value. The angle is recorded by the position sensors of the Lokomat and processed for further assessment. One deficiency of the current Lokomat version is that-for reasons of safety and functionality—range of motion is limited to values typical for human gait. Thus, only patients with limited range of motions can benefit from this Lokomat assessment function. Besides assessment of physiological parameters, this test represents an additional safety feature because contractures and other joint limitations (e.g., due to pain, shortened tendons) become quantifiable and can be used for reducing the risk of joint injury during robot-aided training.

\section{CONCLUSIONS AND OUTLOOK}

Robots can support patient therapy; however, pure automation alone may yield only limited therapeutic improvements. That robots should behave in a humancentered way to maximize therapeutic outcome is assumed. In this article, we suggest enhancing robot-aided treadmill training by two novel human-centered approaches. In the first approach, we suggest that the robot takes into account the patient's individual intentions, efforts, and musculoskeletal properties. In this approach, robot movement and torques that act between robot and patient are measured, processed, and fed back for controlling the robot in a patient-cooperative manner and informing patient and therapist about the voluntary patient efforts (biofeedback). The second approach is the use of robots for recording and providing values for individual performance assessment. Passive and active muscle properties can be recorded before, during, or after training for evaluation of functional status and therapeutic outcome.

The high potential for future robot-aided treadmill training lies in combining both approaches and merging robot-aided training with robot-aided assessment. Thus, only one device is used for both training and assessment. No additional donning and doffing efforts are necessary because the patient can use the training device for assessment before, during, or after therapy. Furthermore, the instrumented robotic actuation makes training, as well as assessment, not only repeatable but also recordable. This is an important prerequisite for the intra- and intersubject comparisons that the therapist requires to evaluate the rehabilitation process. In summary, human-centered rehabilitation robotics has a high potential for making future gait therapy easier, more comfortable, and more efficient. However, broad clinical testing is still required to prove these assumptions.

Future careful clinical evaluations should be performed with a large population of different patient groups, including patients with incomplete paraplegia, patients with hemiplegia after stroke, patients with TBI, and other groups that may benefit, such as patients with MS, CP, and Parkinson's disease. The different human-centered strategies can be compared based on quantitative data (e.g., energy consumption and gait performance) as well as qualitative information from the therapist and patient (e.g., therapist acceptance and patient comfort).

\section{ACKNOWLEDGMENTS}

We thank Marc Lawrence for his contribution to this article.

This material was based on work supported in part by the Commission for Technology and Innovation (CTI), grant 6199.1 MTS, and the National Centres of Competence in Research, Neural Plasticity and Repair, subproject 7, Switzerland.

At the time of the study, Dr. Lünenburger was employed by University of Zurich through a CTI project funded by the Swiss Department of Education and Technology and by Hocoma, AG, which produces the Lokomat. Dr. Colombo is founder, shareholder, and chief executive officer of Hocoma, AG, and coinventor of the Lokomat.

The authors have declared that no competing interests exist.

\section{REFERENCES}

1. Heinzmann J, Zelinsky J. A safe-control paradigm for human-robot interaction. J Intell Robot Syst. 1999;25(4): 295-310.

2. Zinn M, Roth B, Khatib O, Salisbury JK. A new actuation approach for human friendly robot design. Int $\mathrm{J}$ Robot Res. 2004;23(4-5):379-98.

3. Khatib O, Brock O, Chang K-S, Ruspini D, Sentis L, Viji $\mathrm{S}$. Human-centered robotics and interactive haptic simulation. Int J Robot Res. 2004;23(2):167-78.

4. Bien ZZ, Stefanov D, editors. Advances in rehabilitation robotics: Human-friendly technologies on movement 
assistance and restoration for people with disabilities. Berlin (Germany): Springer; 2004.

5. Kawarazaki N, Hoya I, Nishihara K, Yoshidome T. Cooperative welfare robot system using hand gesture instructions. In: Bien ZZ, Stefanov D, editors. Advances in rehabilitation robotics: Human-friendly technologies on movement assistance and restoration for people with disabilities. Berlin (Germany): Springer; 2004. p. 143-53.

6. Hogan N. Impedance control: An approach to manipulation: Part I-Theory. J Dyn Syst Meas Control. 1985;107(1):1-7.

7. Hogan N. Impedance control: An approach to manipulation: Part II-Implementation. J Dyn Syst Meas Control. 1985;107(1):8-16.

8. Hogan N. Impedance control: An approach to manipulation: Part III-Applications. J Dyn Syst Meas Control. 1985;107(1):17-24.

9. Jezernik S, Colombo G, Morari M. Automatic gait-pattern adaptation algorithms for rehabilitation with a 4-DOF robotic orthosis. IEEE Trans Rob Autom. 2004;20(3):574-82.

10. Ikeura R, Monden H, Inooka H. Cooperative motion control of a robot and a human. In: Proceedings of the 3rd IEEE International Workshop on Robot and Human Communication; 1994 Jul 18-20; Nagoya, Japan. New York: IEEE; 1994. p. 112-17.

11. Lum PS, Lehman SL, Reinkensmeyer DJ. The bimanual lifting rehabilitator: An adaptive machine for therapy of stroke patients. IEEE Trans Rehabil Eng. 1995;3(2):166-74.

12. Mokhtari M, Feki MA, Abdulrazak B, Grandjean B. Toward a human-friendly user interface to control an assistive robot in the context of smart homes. In: Bien ZZ, Stefanov D, editors. Advances in rehabilitation robotics: Human-friendly technologies on movement assistance and restoration for people with disabilities. Berlin (Germany): Springer; 2004. p. 47-56.

13. Yoo DH, Hong HS, Kwon HJ, Chung MJ. Humanfriendly care robot system for the elderly. In: Bien ZZ, Stefanov D, editors. Advances in rehabilitation robotics: Human-friendly technologies on movement assistance and restoration for people with disabilities. Berlin (Germany): Springer; 2004. p. 323-32.

14. Barbeau H, Rossignol S. Enhancement of locomotor recovery following spinal cord injury. Curr Opin Neurol. 1994;7(6):517-24. [PMID: 7866583$]$

15. Barbeau H, Ladouceur M, Norman KE, Pepin A, Leroux A. Walking after spinal cord injury: Evaluation, treatment, and functional recovery. Arch Phys Med Rehabil. 1999;80(2):225-35. [PMID: 10025502]

16. Behrman AL, Harkema SJ. Locomotor training after human spinal cord injury: A series of case studies. Phys Ther. 2000;80(7):688-700. [PMID: 10869131]

17. Wernig A, Muller S. Laufband locomotion with body weight support improved walking in persons with severe spinal cord injuries. Paraplegia. 1992;30(4):229-38. [PMID: 1625890]

18. Dietz V, Colombo G, Jensen L. Locomotor activity in spinal man. Lancet. 1994;344(8932):1260-63. [PMID: 7967986]

19. Dietz V, Colombo G, Jensen L, Baumgartner L. Locomotor capacity of spinal cord in paraplegic patients. Ann Neurol. 1995;37(5):574-82. [PMID: 7755351]

20. Field-Fote EC. Spinal cord control of movement: Implications for locomotor rehabilitation following spinal cord injury. Phys Ther. 2000;80(5):477-84. [PMID: 10792858]

21. Finch L, Barbeau H, Arsenault B. Influence of body weight support on normal human gait: Development of a gait retraining strategy. Phys Ther. 1991;71(11):842-55; discussion 855-56. [PMID: 1946621$]$

22. Hesse S, Bertelt C, Schaffrin A, Malezic M, Mauritz KH. Restoration of gait in nonambulatory hemiparetic patients by treadmill training with partial body-weight support. Arch Phys Med Rehabil. 1994;75(10):1087-93. [PMID: 7944913]

23. Hesse S, Bertelt C, Jahnke MT, Schaffrin A, Baake P, Malezic M, Mauritz KH. Treadmill training with partial body weight support compared with physiotherapy in nonambulatory hemiparetic patients. Stroke. 1995;26(6): 976-81. [PMID: 7762049]

24. Da Cunha IT Jr, Lim PA, Qureshy H, Henson H, Monga T, Protas EJ. Gait outcomes after acute stroke rehabilitation with supported treadmill ambulation training: A randomized controlled pilot study. Arch Phys Med Rehabil. 2002;83(9):1258-65. [PMID: 12235606]

25. Visintin M, Barbeau H, Korner-Bitensky N, Mayo NE. A new approach to retrain gait in stroke patients through body weight support and treadmill stimulation. Stroke. 1998;29(6):1122-28. [PMID: 9626282]

26. Laufer Y, Dickstein R, Chefez Y, Marcovitz E. The effect of treadmill training on the ambulation of stroke survivors in the early stages of rehabilitation: A randomized study. J Rehabil Res Dev. 2001;38(1):69-78. [PMID: 11322472]

27. Teixeira da Cunha Filho I, Lim PA, Qureshy H, Henson H, Monga T, Protas EJ. A comparison of regular rehabilitation and regular rehabilitation with supported treadmill ambulation training for acute stroke subjects. J Rehabil Res Dev. 2001;38(2):245-55. [PMID: 11392657]

28. Prokop T, Berger W. Influence of optic flow on locomotion in normal subjects and patients with Parkinson's disease [abstract]. Electroencephalogr Clin Neurophsiol. 1996; 99:370.

29. Wirz M, Zemon DH, Rupp R, Scheel A, Colombo G, Dietz V, Hornby TG. Effectiveness of automated locomotor training in patients with chronic incomplete spinal cord injury: A multicenter trial. Arch Phys Med Rehabil. 2005;86(4):672-80. [PMID: 15827916] 
30. Mayr A, Luenenburger L, Quirinbach E, Matzak KH, Froehlich K, Kofler M, Saltuari L. First experiences with the Lokomat in patients with severe traumatic brain injury. Brain Inj. 2003;17 Suppl 1:46-47.

31. Barbeau H, Visintin M. Optimal outcomes obtained with body-weight support combined with treadmill training in stroke subjects. Arch Phys Med Rehabil. 2003;84(10): 1458-65. [PMID: 14586912]

32. Teasell RW, Bhogal SK, Foley NC, Speechley MR. Gait retraining post stroke. Top Stroke Rehabil. 2003;10(2): 34-65. [PMID: 13680517]

33. Moseley AM, Stark A, Cameron ID, Pollock A. Treadmill training and body weight support for walking after stroke. Cochrane Database Syst Rev. 2003;(4):CD002840. [PMID: 16235304]

34. Dietz V, Mueller R, Colombo G. Locomotor activity in spinal man: Significance of afferent input from joint and load receptors. Brain. 2002;125(Pt 12):2626-34. [PMID: 12429590]

35. Colombo G, Joerg M, Schreier R, Dietz V. Treadmill training of paraplegic patients using a robotic orthosis. J Rehabil Res Dev. 2000;37(6):693-700. [PMID: 11321005]

36. Reinkensmeyer DJ, Wynne JH, Harkema SJ. A robotic tool for studying locomotor adaptation and rehabilitation. In: Proceedings of the Second Joint 24th Annual Conference and the Annual Fall Meeting of the Biomedical Engineering Society and Engineering in Medicine and Biology Society, Vol 3; 2002 Oct 23-26; Houston, TX. New York: IEEE; 2002. p. 2353-54.

37. Reinkensmeyer DJ, Aoyagi D, Emken J, Galvez J, Ichinose W, Kerdanyan G, Nessler J, Maneekobkunwong S, Timoszyk B, Vallance K, Weber R, De Leon R, Bobrow J, Harkema S, Wynne J, Edgerton V. Robotic gait training: Toward more natural movements and optimal training algorithms. In: Proceedings of the 26th Annual International Conference of the Engineering in Medicine and Biology Society, Vol. 7; 2004 Sep 1-5; San Francisco, CA. New York: IEEE; 2004. p. 4818-21.

38. Hesse S, Uhlenbrock D. A mechanized gait trainer for restoration of gait. J Rehabil Res Dev. 2000;37(6):701-8. [PMID: 11321006]

39. Schmidt H, Sorowka D, Hesse S, Bernhardt R. Robotic walking simulator for neurological gait rehabilitation. In: Proceedings of the Second Joint 24th Annual Conference and the Annual Fall Meeting of the Biomedical Engineering Society and Engineering in Medicine and Biology Society, Vol. 3; 2002 Oct 23-26; Houston, TX. New York: IEEE; 2004. p. 2356-57.

40. Boian RF, Bouzit M, Burdea GC, Lewis J, Deutsch JE. Dual Stewart platform mobility simulator. In: Proceedings of the 9th International Conference on Rehabilitation and
Robotics; 2005 Jun 28-Jul 1; Chicago, IL. New York: IEEE; 2005. p. 550-55.

41. Jezernik S, Scharer R, Colombo G, Morari M. Adaptive robotic rehabilitation of locomotion: A clinical study in spinally injured individuals. Spinal Cord. 2003;41(12): 657-66. [PMID: 14639444]

42. Nash MS, Jacobs PL, Johnson BM, Field-Fote EC. Metabolic and cardiac responses to robotic-assisted locomotion in motor-complete tetraplegia: A case report. J Spinal Cord Med. 2004;27(1):78-82. [PMID: 15156941$]$

43. Jacobs PL, Nash MS. Exercise recommendations for individuals with spinal cord injury. Sports Med. 2004;34(11): 727-51. [PMID: 15456347]

44. Hornby TG, Zemon DH, Campbell D. Robotic-assisted, body-weight-supported treadmill training in individuals following motor incomplete spinal cord injury. Phys Ther. 2005;85(1):52-66. [PMID: 15623362]

45. Mayr A, Quirbach E, Kofler M, Saltuari L. First experience with the "Lokomat" gait orthosis in post-acute brain-injured patients [abstract]. Eur J Neurol. 2002;9(Suppl 2):22.

46. Saltuari L. Efficiency of Lokomat training in stroke patients [abstract]. 3rd Joint Congress of Swiss Society of Neurorehabilitation, Austrian Society of Neurorehabilitation, German Society for Neurological Rehabilitation and 1st Regional Meeting of World Federation for NeuroRehabilitation in association with German Speaking Medical Society for Paraplegia in Neurol Rehab. 2004;10(4):169-78.

47. Riener R, Frey M, Bernhardt M, Nef T, Colombo G. Human-centered rehabilitation robotics. In: Proceedings of the 9th International Conference on Rehabilitation and Robotics; 2005 Jun 28-Jul 1; Chicago, IL. New York: IEEE; 2005. p. 319-22.

48. Riener R, Lünenburger L, Jezernik S, Anderschitz M, Colombo G, Dietz V. Patient-cooperative strategies for robot-aided treadmill training: First experimental results. IEEE Trans Neural Syst Rehabil Eng. 2005;13(3):380-94.

49. Riener R, Frey M, Proll T, Regenfelder F, Burgkart R. Phantom-based multimodal interactions for medical education and training: The Munich Knee Joint Simulator. IEEE Trans Inf Technol Biomed. 2004;8(2):208-16. [PMID: 15217266]

50. Krebs HI, Palazzolo JJ, Dipietro L, Ferraro M, Krol J, Rannekleiv K, Volpe BT, Hogan N. Rehabilitation robotics: Performance-based progressive robot-assisted therapy. Auton Rob. 2003;15(1):7-20.

51. Riener R, Fuhr T. Patient-driven control of FES-supported standing up: A simulation study. IEEE Trans Rehabil Eng. 1998;6(2):113-24. [PMID: 9631319]

52. Ferris DP, Gordon KE, Beres-Jones JA, Harkema SJ. Muscle activation during unilateral stepping occurs in the nonstepping limb of humans with clinically complete spinal cord injury. Spinal Cord. 2004;42(1):14-23.

[PMID: 14713939] 
53. Pohl M, Mehrholz J, Ritschel C, Ruckheim S. Speeddependent treadmill training in ambulatory hemiparetic stroke patients: A randomized controlled trial. Stroke. 2002; 33(2):553-58.

54. Cozean CD, Pease WS, Hubbell SL. Biofeedback and functional electric stimulation in stroke rehabilitation. Arch Phys Med Rehabil. 1988;69(6):401-5.

[PMID: 3288172$]$

55. Moreland JD, Thomson MA, Fuoco AR. Electromyographic biofeedback to improve lower extremity function after stroke: A meta-analysis. Arch Phys Med Rehabil. 1998;79(2):134-40. [PMID: 9473993]

56. Mandel AR, Nymark JR, Balmer SJ, Grinnell DM, O’Riain MD. Electromyographic versus rhythmic positional biofeedback in computerized gait retraining with stroke patients. Arch Phys Med Rehabil. 1990;71(9):649-54. [PMID: 2375668]

57. Colborne GR, Olney SJ, Griffin MP. Feedback of ankle joint angle and soleus electromyography in the rehabilitation of hemiplegic gait. Arch Phys Med Rehabil. 1993; 74(10):1100-1106. [PMID: 8215864]

58. Morris ME, Matyas TA, Bach TM, Goldie PA. Electrogoniometric feedback: Its effect on genu recurvatum in stroke. Arch Phys Med Rehabil. 1992;73(12):1147-54. [PMID: 1463378]

59. Aruin AS, Sharma A, Larkins R, Chaudhuri G. Knee position feedback: Its effect on management of pelvic instability in a stroke patient. Disabil Rehabil. 2000;22(15):690-92. [PMID: 11087065]

60. Montoya R, Dupui P, Pages B, Bessou P. Step-length biofeedback device for walk rehabilitation. Med Biol Eng Comput. 1994;32(4):416-20. [PMID: 7967807]

61. Batavia M, Gianutsos JG, Kambouris M. An augmented auditory feedback device. Arch Phys Med Rehabil. 1997; 78(12):1389-92. [PMID: 9421998]

62. Van Peppen RP, Kwakkel G, Wood-Dauphinee S, Hendriks HJ, Van der Wees PJ, Dekker J. The impact of physical therapy on functional outcomes after stroke: What's the evidence? Clin Rehabil. 2004;18(8):833-62.

[PMID: 15609840]

63. Bolek JE. A preliminary study of modification of gait in realtime using surface electromyography. Appl Psychophysiol Biofeedback. 2003;28(2):129-38. [PMID: 12827991]

64. Petrofsky JS. The use of electromyogram biofeedback to reduce Trendelenburg gait. Eur J Appl Physiol. 2001; 85(5):491-95. [PMID: 11606020]

65. Phillips CA, Koubek RJ, Hendershot DM. Walking while using a sensory tactile feedback-system: Potential use with a functional electrical stimulation orthosis. J Biomed Eng. 1991;13(2):91-96. [PMID: 2033956]

66. Hirokawa S, Matsumura K. Biofeedback gait training system for temporal and distance factors. Med Biol Eng Comput. 1989;27(1):8-13. [PMID: 2779301]
67. De Castro MC, Cliquet A Jr. Artificial sensorimotor integration in spinal cord injured subjects through neuromuscular and electrotactile stimulation. Artif Organs. 2000; 24(9):710-17. [PMID: 11012541]

68. Batavia M, Gianutsos JG, Vaccaro A, Gold JT. A do-ityourself membrane-activated auditory feedback device for weight bearing and gait training: A case report. Arch Phys Med Rehabil. 2001;82(4):541-45. [PMID: 11295019]

69. Femery VG, Moretto PG, Hespel JM, Thevenon A, Lensel G. A real-time plantar pressure feedback device for foot unloading. Arch Phys Med Rehabil. 2004;85(10):1724-28. [PMID: 15468038]

70. Jack D, Boian R, Merians AS, Tremaine M, Burdea GC, Adamovich SV, Recce M, Poizner H. Virtual realityenhanced stroke rehabilitation. IEEE Trans Neural Syst Rehabil Eng. 2001;9(3):308-18. [PMID: 11561668]

71. Burdea GC, Popescu V, Hentz V, Colbert K. Virtual reality-based orthopedic telerehabilitation. IEEE Trans Rehabil Eng. 2000;8(3):430-32. [PMID: 11001524]

72. Bardorfer A, Munih M, Zupan A, Primozic A. Upper limb motion analysis using haptic interface. IEEE/ASME Trans Mechatronics. 2001;6(3):253-60.

73. Girone M, Burdea GC, Bouzit M, Popescu V, Deutsch JE. Orthopedic rehabilitation using the "Rutgers ankle" interface. Stud Health Technol Inform. 2000;70:89-95. [PMID: 10977590]

74. Ohsuga M, Tatsuno Y, Shimono F, Hirasawa K, Oyama H, Okamura H. Development of a bedside wellness system. Cyberpsychol Behav. 1998;1(2):105-12.

75. Riva G. Virtual reality in paraplegia: A VR-enhanced orthopaedic appliance for walking and rehabilitation. Stud Health Technol Inform. 1998;58:209-18. [PMID: 10350921]

76. Fung J, Malouin F, McFadyen BJ, Comeau F, Lamontagne A, Chapdelaine S, Beaudoin C, Laurendeau D, Hughey L, Richards CL. Locomotor rehabilitation in a complex virtual environment. In: Proceedings of the 26th Annual International Conference of the Engineering in Medicine and Biology Society, Vol. 2; 2004 Sep 1-5; San Francisco, CA. New York: IEEE; 2004. p. 4859-61.

77. Patton JL, Dawe G, Scharver C, Mussa-Ivaldi F, Kenyon R. Robotics and virtual reality: The development of a lifesized 3-D system for the rehabilitation of motor function. In: Proceedings of the 26th Annual International Conference of the Engineering in Medicine and Biology Society, Vol. 7; 2004 Sep 1-5; San Francisco, CA. New York: IEEE; 2004. p. 4840-43.

78. Keshner EA, Kenyon RV, Dhaher Y. Postural research and rehabilitation in an immersive virtual environment. In: Proceedings of the 26th Annual International Conference of the Engineering in Medicine and Biology Society, Vol. 7; 2004 Sep 1-5; San Francisco, CA. New York: IEEE; 2004. p. 4862-65.

79. Wolf SL, Binder-MacLeod SA. Electromyographic biofeedback applications to the hemiplegic patient. Changes 
in upper extremity neuromuscular and functional status. Phys Ther. 1983;63(9):1393-1403. [PMID: 6611660]

80. Inglis J, Donald MW, Monga TN, Sproul M, Young MJ. Electromyographic biofeedback and physical therapy of the hemiplegic upper limb. Arch Phys Med Rehabil. 1984;65(12):755-59. [PMID: 6391417]

81. Crow JL, Lincoln NB, Nouri FM, De Weerdt W. The effectiveness of EMG biofeedback in the treatment of arm function after stroke. Int Disabil Stud. 1989;11(4):155-60. [PMID: 2701823]

82. Schleenbaker RE, Mainous AG 3rd. Electromyographic biofeedback for neuromuscular reeducation in the hemiplegic stroke patient: A meta-analysis. Arch Phys Med Rehabil. 1993;74(12):1301-4. [PMID: 8259896]

83. Lünenburger L, Colombo G, Riener R, Dietz V. Biofeedback in gait training with the robotic orthosis Lokomat. In: Proceedings of the 26th Annual International Conference of the Engineering in Medicine and Biology Society, Vol. 7; 2004 Sep 1-5; San Francisco, CA. New York: IEEE; 2004. p. 4888-91.

84. Ashworth B. Preliminary trial of carisoprodol in multiple sclerosis. Practitioner. 1964;192:540-42. [PMID: 14143329]

85. Bohannon RW, Smith MB. Interrater reliability of a modified Ashworth scale of muscle spasticity. Phys Ther. 1987;67(2):206-7. [PMID: 3809245]

86. Voerman GE, Gregoric M, Hermens HJ. Neurophysiological methods for the assessment of spasticity: The Hoffmann reflex, the tendon reflex, and the stretch reflex. Disabil Rehabil. 2005;27(1-2):33-68. [PMID: 15799143]

87. Katz RT, Rymer WZ. Spastic hypertonia: Mechanisms and measurement. Arch Phys Med Rehabil. 1989;70(2): 144-55. [PMID: 2644919]

88. Wood DE, Burridge JH, Van Wijck FM, McFadden C, Hitchcock RA, Pandyan AD, Haugh A, Salazar-Torres JJ, Swain ID. Biomechanical approaches applied to the lower and upper limb for the measurement of spasticity: A systematic review of the literature. Disabil Rehabil. 2005; 27(1-2):19-32. [PMID: 15799142]

89. Lance JW. Spasticity: Disordered motor control. Chicago (IL): Year Book Medical Publishers; 1980. p. 185-204.

90. Sanger TD, Delgado MR, Gaebler-Spira D, Hallett M, Mink JW. Classification and definition of disorders causing hypertonia in childhood. Pediatrics. 2003;111(1):89-97. [PMID: 12509602]

91. Dietz V, Young RR. The Syndrome of spastic paresis. In: Brandt T, Caplan LR, Dichgans J, Diener HC, Kennard C, editors. Neurological disorders: Course and treatment. 2nd ed. San Diego (CA): Academic Press; 2003. p. 1247-57.

92. Firoozbakhsh KK, Kunkel CF, Scremin AM, Moneim MS. Isokinetic dynamometric technique for spasticity assessment. Am J Phys Med Rehabil. 1993;72(6):379-85. [PMID: 8260132]

93. Engsberg JR, Olree KS, Ross SA, Park TS. Quantitative clinical measure of spasticity in children with cerebral palsy. Arch Phys Med Rehabil. 1996;77(6):594-99. [PMID: 8831478$]$

94. Perell KL, Scremin AM, Scremin O, Kunkel CF. Quantifying muscle tone in spinal cord injury patients using isokinetic dynamometric techniques. Paraplegia. 1996;34(1): 46-53. [PMID: 8848323]

95. Akman MN, Bengi R, Karatas M, Kilinc S, Sozay S, Ozker R. Assessment of spasticity using isokinetic dynamometry in patients with spinal cord injury. Spinal Cord. 1999;37(9):638-43. [PMID: 10490855]

96. Franzoi AC, Castro C, Cardone C. Isokinetic assessment of spasticity in subjects with traumatic spinal cord injury (ASIA A). Spinal Cord. 1999;37(6):416-20. [PMID: 10432261]

97. Kakebeeke TH, Lechner H, Baumberger M, Denoth J, Michel D, Knecht H. The importance of posture on the isokinetic assessment of spasticity. Spinal Cord. 2002; 40(5):236-43. [PMID: 11987006]

98. Jobin A, Levin MF. Regulation of stretch reflex threshold in elbow flexors in children with cerebral palsy: A new measure of spasticity. Dev Med Child Neurol. 2000; 42(8):531-40. [PMID: 10981931]

99. Mirbagheri MM, Barbeau H, Ladouceur M, Kearney RE. Intrinsic and reflex stiffness in normal and spastic, spinal cord injured subjects. Exp Brain Res. 2001;141(4):446-59. [PMID: 11810139]

100. Kearney RE, Stein RB, Parameswaran L. Identification of intrinsic and reflex contribution to human ankle stiffness dynamics. IEEE Trans Biomed Eng. 1997;44(6):493-504. [PMID: 9151483]

101. Lamontagne A, Malouin F, Richards CL, Dumas F. Evaluation of reflex- and nonreflex-induced muscle resistance to stretch in adults with spinal cord injury using hand-held and isokinetic dynamometry. Phys Ther. 1998;78(9):964-75; discussion 976-78. [PMID: 9736894]

102. Boiteau M, Malouin F, Richards CL. Use of a hand-held dynamometer and a Kin-Com dynamometer for evaluating spastic hypertonia in children: A reliability study. Phys Ther. 1995;75(9):796-802. [PMID: 7659739]

103. Damiano DL, Quinlivan JM, Owen BF, Payne P, Nelson KC, Abel MF. What does the Ashworth scale really measure and are instrumented measures more valid and precise? Dev Med Child Neurol. 2002;44(2):112-18. [PMID: 11848107$]$

104. Riener R, Brunschweiler A, Lünenburger L, Colombo G. Robot-supported spasticity evaluation. In: Proceedings of the 9th Annual Conference of the International FES Society. 2004 Sep; Bournemouth, England. Glendale (CA): IFESS; 2004. p. 287-89.

Submitted for publication February 16, 2005. Accepted in revised form August 15, 2005. 